\title{
Article
}

\section{A Biomechanical Investigation of Selected Lumbopelvic Hip Tests: Implications for the Examination of Walking}

Bailey, Robert Walter, Richards, Jim and Selfe, James

Available at http://clok.uclan.ac.uk/14690/

Bailey, Robert Walter, Richards, Jim ORCID: 0000-0002-4004-3115 and Selfe, James (2016) A Biomechanical Investigation of Selected Lumbopelvic Hip Tests: Implications for the Examination of Walking. Journal of Manipulative and Physiological Therapeutics . ISSN 0161-4754

It is advisable to refer to the publisher's version if you intend to cite from the work. http://dx.doi.org/10.1016/j.jmpt.2016.04.007

For more information about UCLan's research in this area go to http://www.uclan.ac.uk/researchgroups/ and search for <name of research Group>.

For information about Research generally at UCLan please go to http://www.uclan.ac.uk/research/

All outputs in CLoK are protected by Intellectual Property Rights law, including Copyright law. Copyright, IPR and Moral Rights for the works on this site are retained by the individual authors and/or other copyright owners. Terms and conditions for use of this material are defined in the policies page.

\section{CLoK}

Central Lancashire online Knowledge www.clok.uclan.ac.uk

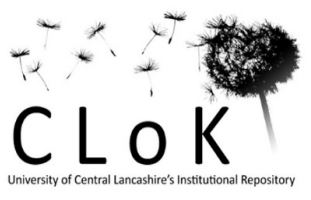




\title{
A Biomechanical InVestigation of Selected LUMBOPELVIC HiP TESTS: IMPLICATIONS FOR THE EXAMINATION OF WALKING
}

\author{
Robert Walter Bailey, PhD, a Jim Richards, PhD, b and James Selfe, PhD
}

Objectives: The purpose of this study was to compare lumbopelvic hip ranges of motion during the Trendelenburg, Single Leg Squat, and Corkscrew Tests to walking and to describe the 3-dimensional lumbopelvic hip motion during the tests. This may help clinicians to select appropriate tests when examining gait.

Methods: An optoelectronic movement analysis tracking system was used to assess the lumbopelvic hip region of 14 healthy participants while performing Trendelenburg, Single Leg Squat, and Corkscrew Tests and walking. The lumbopelvic hip 3-dimensional ranges of movement for the clinical tests were compared with walking using a repeated-measures analysis of variance with pairwise comparisons.

Results: No significant differences were found between the pelvic obliquity during the Trendelenburg Test and walking (Trendelenburg Test: $\mathrm{L}, 11.3^{\circ} \pm 4.8^{\circ}, \mathrm{R}, 10.8^{\circ} \pm 5.0^{\circ}$ vs walk: $\mathrm{L}, 8.3^{\circ} \pm 4.8^{\circ}, \mathrm{R} 8.3^{\circ} \pm 5.1^{\circ}, \mathrm{L}, \mathrm{P}=.143, \mathrm{R}, \mathrm{P}=.068$ ). Significant differences were found between the hip sagittal plane range of movement during the Single Leg Squat and walking (Single Leg Squat: L, $44.2^{\circ} \pm 13.7^{\circ}, \mathrm{R}, 41.7^{\circ} \pm 10.9^{\circ}$ vs walk: $38.6^{\circ} \pm 7.0^{\circ}, \mathrm{R} 37.8^{\circ} \pm 5.1^{\circ}, \mathrm{P}$ b .05 ), the hip coronal plane range of movement (Single Leg Squat: L, 9.1 $\pm 5.8^{\circ}, \mathrm{R}, 9.0^{\circ} \pm 4.6^{\circ}$ vs walk: $\mathrm{L}, 9.4^{\circ} \pm 2.3^{\circ}, \mathrm{R} 9.5^{\circ} \pm 2.0^{\circ}, \mathrm{P}<$ .05 ), and the hip coronal plane range of movement during the Corkscrew Test and walking (Corkscrew: $\mathrm{L}, 5.7^{\circ} \pm 3.3^{\circ}, \mathrm{R}$, $5.7^{\circ} \pm 3.2^{\circ}$ vs walk: $\left.\mathrm{L}, 9.4^{\circ} \pm 2.3^{\circ}, \mathrm{R} 9.5^{\circ} \pm 2.0^{\circ}, \mathrm{P}<.05\right)$.

Conclusions: The results of the present study showed that, in young asymptomatic participants with no known lumbopelvic hip pathology, the pelvic obliquity during the Trendelenburg Test and walking is similar. During the Single Leg Squat, the hip moved more in the sagittal plane and less in the coronal plane when compared with walking. There was more movement in the hip transverse plane movement during the Corkscrew Test than during walking. These results suggest that for the Trendelenburg Test to be interpreted as normal, the pelvis should achieve at least $10^{\circ}$ of pelvic obliquity; during the Single Leg Squat, the hip should move through $43^{\circ}$ in the sagittal plane and under $10^{\circ}$ in the coronal plane; and for the Corkscrew Test to be interpreted as normal, the hip should move through $6^{\circ}$ of rotation and the trunk through $27^{\circ}$ of rotation. (J Manipulative Physiol Ther 2016;xx:1-9)

Key Indexing Terms: Lumbopelvic Hip; Range of Motion; Articular; Biomechanical Phenomena

Clinicians commonly use tests including the Trendelenburg, Single Leg Squat,2 and Cork- screw Tests during the examination of the lumbopelvic and hip complex. These tests are used to examine the movements of the lumbar, pelvic, and hip regions in a weight-bearing position.1-4 They may be used in isolation5,6 or to compliment the examination of functional tasks including walking.3,7 The clinical assumption is that the lumbar, pelvic, and hip movements generated during these tests are similar to those of walking.3 However, there are few biomechanical investigations of the normative kinematics of these tests and a limited number of previous studies that compare the kinematics of these tests to walking.8

The Trendelenburg Test is interpreted by observing pelvic obliquity during the test.3,9 Two previous studies have objectively defined when the pelvic drop (obliquity) becomes positive. Asayama et al5 stated that a "tilt angle" (pelvic obliquity) of greater than $2^{\circ}$ indicated a positive Trendelenburg Test result. Westhoff et al 10 stated that "Pelvic drop to the swinging limb during single stance phase of more than $4^{\circ}$ and/or maximum (peak value) pelvic drop in the stance phase of more than $8^{\circ}$ " indicated a positive test result. There are no published data quantifying sagittal and transverse plane pelvic movement during the Trendelenburg Test. The Single Leg Squat is currently interpreted by observing hip range of movement in the sagittal and coronal planes. Only 1 study, that of Livengood et al, 4 has objectively defined when the Single Leg Squat becomes positive: hip flexion greater than $65^{\circ}$, hip abduction/adduction greater than $10^{\circ}$, and knee valgus/varus greater than $10^{\circ}$. There are no published data for sagittal, coronal, and transverse plane pelvic movement during the Single Leg Squat. The Trendelenburg Test requires neuromuscular control of the pelvis in the coronal plane, and the Single Leg Squat requires control of the hip in the sagittal plane. Interestingly, there are currently no existing tests for neuromuscular control of the pelvis requiring hip internal-external rotation movement in the transverse plane documented within the musculoskeletal literature. Hence, a novel clinical test for the assessment of the 
lumbopelvic and hip region in the transverse plane has started to be used within clinical practice. This test has been termed the Corkscrew Test. The method for performing the Corkscrew Test is based upon the Single Leg Squat, 4 and its interpretation is based upon the Single Leg Squat criterion in combination with kinematic values found within the walking literature. 11-13 The participant stands on the limb being evaluated, with the contralateral leg lifted off the ground, as if walking. The participant rotates the weight-bearing hip first into maximal hip internal rotation and then external rotation, and returns to the start position in less than 6 seconds. The Corkscrew Test is a new test; hence, there are currently no kinematic data to support its use in clinical practice.

Pathologies affecting the lumbopelvic and hip complex include ankylosing spondylitis, 14,15 Perthes disease, 16,17 and slipped femoral epiphysis. 18-20 These pathologies have been found to be 3 times more prevalent in late teenage males when compared with females14,17,20,21 and associated with changes in gait.3 To recommend the use of these tests within clinical practice, there is a need to establish the normal ranges of movement for the tests, particularly in young males, and to compare these to those found during walking. Previous studies of these clinical tests5,10 and gait11-13 have described the ranges of movement to 1 standard deviation. Individuals found to exhibit ranges of movement in excess of 1 standard deviation from the clinical test's normative value could be interpreted as exhibiting an abnormal movement pattern. This will allow clinicians to interpret the tests, identify abnormal responses, subgroup individuals, and better understand their role in the examination of gait.

The purpose of this study was to investigate the biomechanical characteristics of the Trendelenburg, Single Leg Squat, and Corkscrew Tests and their relationship to the kinematics of walking. It was hypothesized that the pelvic obliquity achieved during the Trendelenburg Test, the hip sagittal and coronal plane range of movement during the Single Leg Squat, and the hip rotation range during the Corkscrew Test should be similar to these parameters when walking.

\section{METHODS \\ Participants}

Participants were recruited via posters within the university campus. All participants were informed about the purposes and procedures of the study, having signed the informed consent. The study had the approval of the University of Central Lancashire, UK (number: FHEC-188), regarding the protection of the rights of the participants and the confidentiality of the data. All data collection conformed to the Declaration of Helsinki. This study was approved by the Human subjects, University of Central Lancashire, Preston, UK. Prior to testing, each participant completed a health screening questionnaire to confirm that they were injury free, that they had no diagnosed balance disorder or leg length discrepancy, and that they did not have any pre-existing medical condition that would prevent them from participating.22,23,23-26 Subsequently, 14 healthy male participants were recruited (age, $20.5 \pm 2.0$ years; height, $1.76 \pm 0.13 \mathrm{~m}$; mass, $73.9 \pm 9.0 \mathrm{~kg}$ ) who had no pain or neuromusculoskeletal disorder.

\section{Instrumentation}

Kinematic data were collected using a 10-camera ProReflex system (QualisysMedical AB, Gothenburg, Sweden) at $100 \mathrm{~Hz}$. Force data were collected using an AMTI force platform (Advanced Mechanical Technology, Inc, Watertown, MA; model BP400600). Force data were used to define the events of heel strike and toe off. 


\section{Modelling of the Lower Limbs and Joints}

The segments of the lower limbs were modeled based on the calibrated anatomical systems technique. 27 The land marks used included (Fig 1) medial and lateral femoral epicondyles, greater trochanter, and anterior and posterior superior iliac spines of the pelvis. Clusters of 4 markers mounted on rigid plastic shells were attached to each segment (Fig 1). After placing all of the markers, a calibration was performed that consisted of data collection for 1 second with the participant standing in the anatomic position. This defined the anatomic coordinate systems that enabled the position and orientation of each segment in space to be identified.27 Local coordinate systems were defined for all segments of the model, with the y-axis equal to anterior-posterior, $x$-axis equal to medial-lateral, and z-axis equal to proximal-distal. The centers of the knee and ankle joints were calculated as the mean distance between the medial and lateral joint markers. The center of the hip joint was calculated based on pelvic depth and width using the regression equations developed by Bell et al.28,29 Joint kinematics were calculated using a Cardan/Euler method with an XYZ order of rotations.

\section{Procedures}

Testing was divided into 2 groups of tests: the "clinical tests"were the Trendelenburg Test, Single Leg Squat, and Corkscrew Test; the "functional test" was walking. The order of the clinical tests was randomized using a pseudorandom number generator.30

\section{Protocol}

Prior to commencing the tests, each participant was provided with standardized oral instructions. For the clinical tests, participants completed 3 practice trials to become familiar with the procedure, followed by 3 trials of each test.

\section{Clinical Tests: Trendelenburg Test, Single Leg Squat, and Corkscrew Test}

Participants were asked to stand on the edge of the laboratory force plates near the center of the data collection area; this formed the start position for the test. Participants were not instructed which leg to use first during the tests. Participants completed the tests by stepping onto the laboratory force plates, performing the test on both limbs consecutively, and stepping back off the force plates to the start position. This reflected how the tests are routinely completed in clinical practice (Figs 2-4). Data capture commenced when the participant started to step onto the force plate for a duration of 75 seconds for the Trendelenburg Test, 40 seconds for the Single Leg Squat, and 15 seconds for the Corkscrew Test. The participants were allowed a 30-second rest between clinical tests to avoid fatigue. The markers were left in position on the participants between the functional and clinical tests to minimize any errors in marker placement.

\section{Functional Test: Walking}

Participants were asked to stand at a preset position $5 \mathrm{~m}$ from the data collection area; this formed the start position for the test. The finish position for the test was $10 \mathrm{~m}$ from the start position. Participants were not instructed which leg to take the first step with.

Data capture commenced when the participant was approximately $1 \mathrm{~m}$ outside of the data collection area and stopped when the participant reached the finish position. This ensured that the participants were in a steady state of gait. The participants were allowed a 1-minute rest between functional tests to avoid fatigue. 


\section{Data Processing}

The movement data were exported to Visual3D (C-Motion, Inc, Germantown, MD) for processing.

The movement data were filtered using a second-order, low-pass Butterworth filter with a 6-Hz cutoff frequency. The trunk, lumbar, thoracic, and hip angles were calculated relative to the local coordinate system, and the pelvic angles were calculated relative to the global coordinate system. The local coordinate system data provide information about movement of one segment relative to the next, whereas the global coordinate system data provide information on the orientation of the segment relative to the ground.

For all tests, the data were normalized for time to 101 points. For walking, this was between heel strike to toe off; for the Trendelenburg Test, this was the range movement starting from maximum pelvic obliquity over a 30-second duration; for the Single Leg Squat, this was between minimum and maximum hip flexion; and for the Corkscrew Test, this was between minimum and maximum hip rotation.

\section{Statistical Analysis}

The data from the Visual 3D software were exported to Microsoft Excel 2003 to extract peak value and minimum mean values for each participant. The ranges of movements were established by calculating the difference between extracted peak value and minimum mean values for each parameter. The ranges of movement found in the clinical tests were compared with those of walking by a repeated-measures analysis of variance with post hoc pairwise comparisons. A Bonferroni adjustment was used to account for multiple comparisons and to reduce the possibility of type I errors. Adjusted P values were reported. The $\alpha$ level was set at .05. All statistical analyses were performed using SPSS version 16.0.

\section{RESULTS}

Table 1 shows the normative data of the clinical tests and pairwise comparisons between the clinical tests and walking.

The mean and standard deviations for the clinical tests and pairwise comparisons between the clinical tests and walking are presented in Table 1. Significant differences were seen between the Trendelenburg Test and walking in the coronal and transverse planes for the lumbar, thoracic, and trunk ranges of motion. For the pelvis in the sagittal and transverse planes and for the hip in all 3 cardinal planes. 374

For the Single Leg Squat, significant differences were also found in the lumbar spine in the sagittal and transverse planes, thoracic spine in the coronal plane, and trunk in all 3 cardinal planes ranges of motion. For the pelvis in the coronal and transverse planes and at the hip in the sagittal and transverse planes.

Significant differences were also seen between the Corkscrew Test and walking in the transverse planes for the lumbar and thoracic ranges of motion. For the trunk in the coronal and transverse planes, for the pelvis in the sagittal and transverse planes, and for the hip in the sagittal and coronal planes.

\section{DISCUSSION}

The Trendelenburg Test is currently interpreted by the orientation of the pelvis compared with the horizontal (pelvic obliquity)3; therefore, pelvic obliquity is currently a value normally quoted within research5,10 and a clinically important parameter for clinicians when examining the components of walking.3 Current research states that the Trendelenburg Test is positive if the pelvic obliquity is between $2^{\circ} 5$ and $4^{\circ} .10$ The pelvic obliquity found in this study was large and symmetrical for the Trendelenburg Test: left $11.3^{\circ}(\mathrm{SD}=4.81)$, right $10.8^{\circ}$ 
$(\mathrm{SD}=4.96)$. The existing evidence base advocates lower values of pelvic obliquity for the interpretation of the test when compared with this study.

This disagreement may be explained by the population studied; the participants in Asayama et al were post total hip arthroplasty, the study of Westhoff et al used participants with Legg-Calve-Perthes disease, but this current study was of healthy participants. However, if the angle that needs to be achieved is amended to fit within 1 standard deviation of the results of this study, then the pelvic obliquity value would become $6^{\circ}$ and hence would be in keeping with the previous studies. Based on this current study's results, it could therefore be suggested that the Trendelenburg Test should be interpreted as positive if the participant is unable to achieve a value of $10^{\circ}$ or more for pelvic obliquity.

The Hardcastle and Nade method for performing the Trendelenburg Test does not describe the required position or movements of the other regions during the test. There have been no previous studies that have reported the trunk, lumbar, thoracic, pelvis, or hip range of movement in the sagittal, coronal, or transverse planes during the Trendelenburg Test. However, it is a common clinical assumption that the participant should maintain an upright posture and minimal movement in all planes during the test. This study found the lumbar, thoracic, trunk, pelvis, and hip ranges of movement to be small and symmetrical in the 3 cardinal planes of movement during the Trendelenburg Test. Hence, when performing the Trendelenburg Test clinically, there should be no observable movement of the participant except at the pelvis in the coronal plane. Consequently, during the Trendelenburg Test, the participant should appear to be in a position of pelvic obliquity but not moving.

When considering clinical assessment of walking, the Trendelenburg Test was found to be an appropriate proxy for examining the lumbar, thoracic, and trunk sagittal plane ranges of movement; the pelvis coronal plane range of movement; and both the lumbar coronal plane and pelvic obliquity components. Trendelenburg originally developed his test to examine the pelvic obliquity component of walking. This study confirmed that the Trendelenburg Test is appropriate for examining the pelvic obliquity of walking as Trendelenburg intended it for. For the Trendelenburg Test to be interpreted clinically as normal, the pelvis should achieve a position of at least $10^{\circ}$ of pelvic obliquity, and there should be no observable movement of the participant in any of the 3 cardinal planes while maintaining this position.

Currently, the Single Leg Squat is interpreted as excellent if the individual exhibits more than $65^{\circ}$ of hip flexion and a coronal plane range of movement of less than $10^{\circ} .4$ The hip flexion ranges of movement found in this study were large and symmetrical for the Single Leg Squat: left $44.2^{\circ}(\mathrm{SD}=13.70)$, right $41.7^{\circ}(\mathrm{SD}=10.89)$, and moderate and symmetrical in the coronal plane: left $9.1^{\circ}(\mathrm{SD}=5.76)$, right $9.0^{\circ}(\mathrm{SD}=4.55)$.

The limited number of previous studies available has advocated higher values for hip sagittal range of movement and similar coronal plane ranges of movement for the interpretation of the test. However, the previously published Single Leg Squat articles were not kinematic studies. The values published by Livengood et al 4 were derived from clinical experience. Interestingly, if the hip flexion angle that needs to be achieved is amended to fit within 1 standard deviation, then the hip sagittal plane ranges of movement would become $56^{\circ}$ but still remain lower than previous studies' stated value. Based on the kinematic data generated in this study, it could be recommended that the Single Leg Squat should be interpreted as normal if the individual is able to achieve $43^{\circ}$ of hip sagittal plane range of movement while maintaining under $10^{\circ}$ of hip coronal plane movement.

The method of Livengood et al for performing the Single Leg Squat does not describe the required position or movements of the other regions during the test. There have been no previous studies that report trunk, lumbar, thoracic, or pelvic range of movement in the sagittal, coronal, or transverse planes during the Single Leg Squat. However, it is a common clinical assumption that participants should maintain an upright posture and exhibit minimal movement in the 3 cardinal planes. This study found the trunk, lumbar, thoracic, and pelvis ranges of movement to be moderate and symmetrical in the 3 cardinal planes of movement during the Single Leg Squat. Hence, when using the Single Leg Squat during clinical assessment, some movement of the participant in all of the regions is normal with a large movement of the hip in the sagittal plane. 
When considering examining walking, the Single Leg Squat was found to be an appropriate proxy for examining the lumbar coronal plane, thoracic sagittal and transverse plane, and hip coronal plane ranges of movement. Therefore, this study has found that the Single Leg Squat is an appropriate test to examine the hip for coronal plane range of walking. However, its utility is limited to the coronal plane because it was not found to be a good representation of walking for the hip in the sagittal or transverse planes. For the Single Leg Squat to be interpreted as normal, the hip should move through $43^{\circ}$ in the sagittal plane, not exceed $10^{\circ}$ of hip coronal plane movement, and allow a small amount of movement in the trunk and pelvis in all other planes.

There are no previous kinematic studies of the movements occurring during the Corkscrew Test.

The hip transverse plane range of movement values found in this study were large and symmetrical for the Corkscrew Test: left $8.3^{\circ}(\mathrm{SD}=3.50)$, right $6.4^{\circ}(\mathrm{SD}=3.30)$. It was presumed a priori that the hip transverse plane movements during the Corkscrew Test and walking would be similar, $10^{\circ}$. The hip coronal plane range of movement was predicted to be similar to that observed during the Single Leg Squat, $10^{\circ} .4$ However, both the hip transverse plane movements: left $8.3^{\circ}(\mathrm{SD}=3.50)$, right $6.4^{\circ}(\mathrm{SD}=3.30)$, and coronal plane movements: left $5.7^{\circ}(\mathrm{SD}=3.26)$, right $5.7(\mathrm{SD}=3.17)$, found in this study were smaller than those predicted a priori. Most of the transverse plane movement occurred in the trunk: left $26.1^{\circ}(\mathrm{SD}=17.40)$, right $28.8^{\circ}(\mathrm{SD}=16.00)$, and therefore, the Corkscrew Test appears to be a greater challenge of trunk rather than hip transverse plane movement. Subsequent to this study, the Corkscrew Test could be interpreted as positive if the individual is unable to achieve $6^{\circ}$ of hip rotation. However, if the angle that needs to be achieved is amended to fit within 1 standard deviation, then the hip transverse plane range of movement would become $9^{\circ}$ and hence would be in keeping with the values predicted a priori.

The current method for performing the Corkscrew Test does not describe the required position or movements of the other regions during the test. There have been no previous studies that have reported on the trunk, lumbar, thoracic, pelvis, or hip kinematics during the Corkscrew Test. However, as the test is becoming more commonly used in clinical practice, it is being assumed by clinicians that participants should maintain an upright posture during the test. This study found the sagittal and coronal plane ranges of movement to be symmetrical and either moderate or small for all of the regions during the Corkscrew Test.

When using the Corkscrew Test clinically, therefore, there should be some observable movement of the participant in each of the regions and cardinal planes with a large amount of movement being observed in the trunk and thoracic spine in the transverse plane.

When considering walking, the Corkscrew Test was found to be an appropriate proxy for examining the trunk and lumbar sagittal plane ranges of movement. For the Corkscrew Test to be assessed as normal, the hip should move through $6^{\circ}$ of rotation and the trunk through $27^{\circ}$ of rotation. There should be some observable movement of the participant in the each of the 3 cardinal planes while maintaining this position.

From this study, the Trendelenburg Test and Single Leg Squat were found to examine different, complementary ranges of lumbopelvic and hip movement. The clinical application of this is that, when used in isolation, these tests do not allow a full examination of the individual. However, when used in combination, these 2 tests enable examination of all but 1 region and plane. The only parameter that this combination of tests was found inappropriate to examine was the thoracic sagittal plane range of movement. However, none of the clinical tests were appropriate for this parameter. Clinicians may wish to use alternative tests to examine this parameter of walking. Clinicians commonly use lumbopelvic hip tests to examine components of the walking gait cycle.1 However, little was known about the exact biomechanics of the tests within young, healthy males and their relationship to the gait cycle. This study established that, when a clinician uses these clinical tests as part of the examination of young, healthy males, for the Trendelenburg Test to be interpreted as normal, the pelvis should achieve a position of at least $10^{\circ}$ of pelvic obliquity, and there should be no observable movement in any of the 3 cardinal planes while maintaining this position. For the Single Leg Squat to be interpreted as normal, the hip should move through $43^{\circ}$ in the sagittal plane and under $10^{\circ}$ in the coronal plane. For the Corkscrew Test to be interpreted as normal, the hip should move through $6^{\circ}$ of rotation and the trunk through $27^{\circ}$ of rotation. Individuals who exhibit movements in excess of these normative values could be interpreted by clinicians as 
having hypermobility in that region; those who demonstrate less movement could be interpreted as being hypomobile. Using the data from this study may aid subgrouping patients in clinical practice, leading to targeted interventions, which may improve outcome in musculoskeletal patients. Of clinical interest, previous studies have found differences in non-weight-bearing, passive, clinical test's lumbopelvic hip kinematics when comparing between healthy male participants and athletes including professional football players. 31 Nevin and Delahunt32 found that asymptomatic football players exhibited significantly reduced hip internal and external rotation range of movement when compared with healthy participants. A longitudinal study by Ibrahim et al 33 found that professional football players exhibited reduced hip internal-external rotation range of movement when compared with healthy male participants. Further investigations regarding the lumbopelvic hip tests and their relationship to gait should consider if professional football players exhibit hypomobile hip ranges of movement during the weight-bearing clinical tests and if the lumbar, pelvic, and hip movements generated during these tests are similar to those of walking in this specific subgroup of the healthy population.

\section{Limitations}

A limitation of this study is due to methodological constraints in data acquisition. Lumbopelvic and hip movement is the result of movements occurring at the lumbar spine, pelvis, hip, and sacroiliac joints. No sensor was coupled to the sacrum; hence, the contribution of the sacroiliac joint to the overall lumbopelvic and hip movement could not be measured. However, to fully characterize lumbopelvic and hip movement, this should be addressed in the future. Furthermore, this study was conducted in a small sample of young males with normal movement. Caution is needed when generalizing these findings to other populations such as older adults or females.

\section{CONCLUSION}

The results of the present study showed that, in young, healthy male participants, the pelvic obliquity during the Trendelenburg Test and the hip coronal plane range of movement during the Single Leg Squat are similar to these components of walking. Hence, the Trendelenburg Test is an appropriate proxy clinical test for examining the pelvic obliquity component of walking and the Single Leg Squat for the hip coronal plane range of movement. However, the hip flexion range of movement found during the Single Leg Squat and hip rotation during the Corkscrew Test were different to walking. Therefore, the Single Leg Squat and Corkscrew Tests should not be used to examine these components of walking. Such information needs to be considered when using these tests clinically during the examination of this population. Using the Trendelenburg Test and Single Leg Squat in combination allows clinicians to more fully examine the lumbopelvic hip components of walking.

\section{Practical Applications}

- This study found that the pelvic obliquity during the Trendelenburg Test and walking is similar. During the Single Leg Squat, the hip moved more in the sagittal plane and less in the coronal plane than during walking. - There was more hip movement in the transverse plane during the Corkscrew Test than during walking.

- These results suggest that the Trendelenburg Test may be used to assess the pelvic obliquity of walking, but the Single Leg Squat is not an appropriate test for the hip sagittal or coronal plane movement and the Corkscrew Test is not appropriate for hip movement in the transverse plane.

\section{CONTRIBUTORSHIP INFORMATION}

Concept development (provided idea for the research): R.B.

Design (planned the methods to generate the results): R.B., J.R.

Supervision (provided oversight, responsible for organization and implementation, writing of the manuscript): J.R., J.S., J.B.

Data collection/processing (responsible for experiments, patient management, organization, or reporting data): 
R.B.

Analysis/interpretation (responsible for statistical analysis, evaluation, and presentation of the results): R.B.

Literature search (performed the literature search): R.B.

Writing (responsible for writing a substantive part of the manuscript): R.B.

Critical review (revised manuscript for intellectual content; this does not relate to spelling and grammar checking): R.B.

\section{REFERENCES}

1. Bailey R, Selfe J, Richards J. The role of the Trendelenburg Test in the examination of gait. Phys Ther Rev 2009;14:1907.

2. Bailey R, Richards J, Selfe J. The single leg squat test in the assessment of musculoskeletal function: a review. Physiother Pract Res 2011;32:18-23.

3. Hardcastle P, Nade S. The significance of the Trendelenburg test. J Bone Joint Surg (Br) 1985;67-B:741-6.

4. Livengood AL, DiMattia MA, Uhl TL. "Dynamic Trendelenburg": single-leg-squat test for gluteus medius strength. Athl Ther Today 2004;9:24-5.

5. Asayama I, Naito M, Fujisawa M, Kambe T. Relationship between radiographic measurements of reconstructed hip joint position and the Trendelenburg sign. J Arthroplast 2002;17:747-51.

6. Roussel NA, Nijs J, Truijen S, Smeuninx L, Stassijns G. Low back pain: clinimetric properties of the Trendelenburg test, active straight leg raise test, and breathing pattern during active straight leg raising. J Manip Physiol Ther 2007;30:270-8.

7. Bagatur AE, Zorer G. Distal and lateral advancement of the greater trochanter for the treatment of a positive Trendelenburg's sign and the gluteus medius lurch. J Bone Joint Surg 2003;85:271.

8. Alexander B, Crossley K, Schache A. Comparison of hip and knee biomechanics during gait for "good" and "poor" performers on a single leg squat task: a pilot study. J Sci Med Sport 2009;12:S30.

9. Trendelenburg F. Ueber den gang bei angeborener huftgelenk-sulxation. Dtsch Med Wochenschr 1895;21:21-4.

10. Westhoff B, Petermann A, Hirsch MA, Willers R, Krauspe R.

Computerized gait analysis in Legg Calve Perthes disease — analysis of the frontal plane. Gait Posture 2005 [in press, corrected proof].

11. Kadaba MP, Ramakrishnan HK, Wootten ME. Measurement of lower extremity kinematics during level walking. J Orthop Res 1990;8:383-92.

12. Jacobsen JSN, Nielsen D, Sorensen H, Soballe K, Mechlenburg I. Joint kinematics and kinetics during walking and running in 32 patients with hip dysplasia 1 year after periacetabular osteotomy. Acta Orthop 2014;85:592-9.

13. Ornetti P, Laroche D, Morisset C, Beis JN, Tavernier C, Maillefert JF. Three-dimensional kinematics of the lower limbs in hip osteoarthritis during walking. J Back Musculoskelet Rehabil 2011;24:201-8.

14. Vosse D, Feldtkeller E, Erlendsson J, Geusens P, van der Linden S. Clinical vertebral fractures in patients with ankylosing spondylitis. J Rheumatol 2004;31:1981-5.

15. Ulu MA, Batmaz I, Dilek B, Çevik R. Prevalence of osteoporosis and vertebral fractures and related factors in patients with ankylosing spondylitis. Chin Med J 2014;127: 2740-7.

16. Landin LA, Danielsson LG, Wattsgard CECI. Transient synovitis of the hip. Its incidence, epidemiology and relation to Perthes' disease. J Bone Joint Surg Br 1987;69:238-42.

17. Wynne-Davies R, Gormley J. The aetiology of Perthes' disease. Genetic, epidemiological and growth factors in 310 Edinburgh and Glasgow patients. J Bone Joint Surg Br 1978;60:6-14.

18. Hagglund GUNN, Hansson LI, Ordeberg GUNN, Sandstrom STAF. Bilaterality in slipped upper femoral epiphysis. J Bone Joint Surg Br 1988;70:179-81.

19. Loder RT, Aronsson DD, Dobbs MB, Weinstein SL. Slipped capital femoral epiphysis. Bone Joint Surg 2000;82:1170.

20. Song KS, Oh CW, Lee HJ, Kim SD, Multicenter Study Committee of the Korean Pediatric Orthopedic Society.

Epidemiology and demographics of slipped capital femoral epiphysis in Korea: a multicenter study by the Korean Pediatric Orthopedic Society. J Pediatr Orthop 2009;29:683-6.

21. Wiig O, Terjesen T, Svenningsen S, Lie SA. The epidemiology and aetiology of Perthes disease in Norway: a nationwide study of 425 patients. J Bone Joint Surg Br 2006;88:1217-23.

22. Greenhalgh S, Selfe J. Malignant myeloma of the spine. Physiotherapy 2003;89:486-8.

23. McDonnell MW-FA. Effects of partial foot anaesthesia on normal gait. Physiother 2000;46:115-20.

24. Thomas K, Lee RYW. Fatigue of abdominal and paraspinal muscles during sustained loading of the trunk in the coronal plane. Arch Phys Med Rehabil 2000;81:916-20.

25. Perry SBERATP2. Hormone replacement and strength training positively influence balance during gait in post 
menopausal females: a pilot study. J Sports Sci Med 2009;4:372-81.

26. Maitland GD, Brewerton DA, Graham J, Edwards BC. Vertebral manipulation. Butterworths London; 1986.

27. Cappozzo A, Catani F, la Croce U, Leardini A. Position and orientation in space of bones during movement: anatomical frame definition and determination. Clin Biomech 1995;10:171-8.

28. Bell AL, Brand RA, Pedersen DR. Prediction of hip joint centre location from external landmarks. Hum Mov Sci 1989;8:3-16.

29. Bell AL, Pedersen DR, Brand RA. A comparison of the accuracy of several hip center location prediction methods. J

Biomech 1990;23:617-21.

30. Hill I, Wichmann B. Algorithm AS 183. An efficient and portable pseudo-random number generator. Appl Stat 1982;31:188-90.

31. DiMattia MA, Livengood AL, Uhl TL, Mattacola CG, Malone TR. What are the validity of the single-leg-squat test and its relationship to hip-abduction strength? J Sport Rehabil 2005;14:108-23.

32. Nevin F, Delahunt E. Adductor squeeze test values and hip joint range of motion in Gaelic football athletes with longstanding groin pain. J Sci Med Sport 2014;17:155-9.

33. Ibrahim A, Murrell GAC, Knapman P. Adductor strain and hip range of movement in male professional soccer players. J Orthop Surg 2007;15:46-9.

Table 1. Results: Clinical Tests and Walking Normative Data

\begin{tabular}{|c|c|c|c|c|c|c|c|c|c|}
\hline & & \multicolumn{2}{|c|}{ Trendelenburg Test } & \multicolumn{2}{|c|}{ Single Leg Squat } & \multicolumn{2}{|c|}{ Corkscrew } & \multicolumn{2}{|c|}{ Walking } \\
\hline $\begin{array}{l}\text { Dependent } \\
\text { variable }\end{array}$ & Plane & $\begin{array}{l}\text { Left Mean } \\
\text { (sd) }\end{array}$ & $\begin{array}{c}\text { Right } \\
\text { Mean } \\
\text { (sd) }\end{array}$ & $\begin{array}{l}\text { Left } \\
\text { Mean } \\
\text { (sd) }\end{array}$ & $\begin{array}{l}\text { Right } \\
\text { Mean } \\
\text { (sd) }\end{array}$ & $\begin{array}{l}\text { Left } \\
\text { Mean } \\
\text { (sd) }\end{array}$ & $\begin{array}{l}\text { Right } \\
\text { Mean } \\
\text { (sd) }\end{array}$ & $\begin{array}{l}\text { Left } \\
\text { Mean } \\
\text { (sd) }\end{array}$ & $\begin{array}{l}\text { Right } \\
\text { Mean } \\
\text { (sd) }\end{array}$ \\
\hline $\begin{array}{l}\text { Lumbar } \\
\text { angle range } \\
\left({ }^{\circ}\right)\end{array}$ & $\begin{array}{l}\text { Sagitt } \\
\text { al }\end{array}$ & $2.1(0.95)$ & $\begin{array}{c}2.2 \\
(1.04)\end{array}$ & $\begin{array}{c}11.7 \\
(5.00) *\end{array}$ & $\begin{array}{c}12.6 \\
(5.05)^{*}\end{array}$ & $\begin{array}{c}3.6 \\
(2.11)\end{array}$ & $\begin{array}{c}4.0 \\
(2.03)\end{array}$ & $\begin{array}{c}4.0 \\
(1.52)\end{array}$ & $\begin{array}{c}3.7 \\
(1.47)\end{array}$ \\
\hline $\begin{array}{l}\text { Lumbar } \\
\text { angle range } \\
\left({ }^{\circ}\right)\end{array}$ & $\begin{array}{l}\text { Coron } \\
\text { al }\end{array}$ & $\begin{array}{c}1.8 \\
(1.33)^{*}\end{array}$ & $\begin{array}{c}2.3 \\
(1.49)^{*}\end{array}$ & $\begin{array}{c}4.4 \\
(1.88)\end{array}$ & $\begin{array}{c}4.9 \\
(2.99)\end{array}$ & $\begin{array}{c}6.4 \\
(3.50) *\end{array}$ & $\begin{array}{c}6.5^{0} \\
(5.55)\end{array}$ & $\begin{array}{c}4.8 \\
(2.16)\end{array}$ & $\begin{array}{c}4.7 \\
(2.07)\end{array}$ \\
\hline $\begin{array}{l}\text { Lumbar } \\
\text { angle range } \\
\left({ }^{\circ}\right)\end{array}$ & $\begin{array}{l}\text { Trans } \\
\text { verse }\end{array}$ & $\begin{array}{c}1.6 \\
(0.52)^{*}\end{array}$ & $\begin{array}{c}1.5 \\
(0.74)^{*}\end{array}$ & $\begin{array}{c}4.8 \\
(2.26)^{*}\end{array}$ & $\begin{array}{c}4.9^{0} \\
(1.76)^{*}\end{array}$ & $\begin{array}{c}26.1 \\
(17.40) \\
*\end{array}$ & $\begin{array}{c}28.8 \\
(16.00) \\
*\end{array}$ & $\begin{array}{c}7.9 \\
(2.47)\end{array}$ & $\begin{array}{c}7.8 \\
(2.50)\end{array}$ \\
\hline $\begin{array}{l}\text { Thoracic } \\
\text { angle range } \\
\left({ }^{\circ}\right)\end{array}$ & $\begin{array}{l}\text { Sagitt } \\
\text { al }\end{array}$ & $3.3(2.12)$ & $\begin{array}{c}4.4 \\
(2.52)\end{array}$ & $\begin{array}{c}4.8 \\
(2.81)\end{array}$ & $\begin{array}{c}4.8 \\
(3.00)\end{array}$ & $\begin{array}{c}4.1 \\
(1.95)\end{array}$ & $\begin{array}{c}3.9 \\
(1.49)^{*}\end{array}$ & $\begin{array}{c}4.5 \\
(1.96)\end{array}$ & $\begin{array}{c}3.7 \\
(1.36)\end{array}$ \\
\hline $\begin{array}{l}\text { Thoracic } \\
\text { angle range } \\
\left({ }^{\circ}\right)\end{array}$ & $\begin{array}{l}\text { Coron } \\
\text { al }\end{array}$ & $\begin{array}{c}3.6(0.78) \\
*\end{array}$ & $\begin{array}{c}3.4^{0} \\
(2.03)^{*}\end{array}$ & $\begin{array}{c}3.7 \\
(2.01)^{*}\end{array}$ & $\begin{array}{c}3.3 \\
(2.07)^{*}\end{array}$ & $\begin{array}{c}2.8 \\
(1.34)\end{array}$ & $\begin{array}{c}3.5 \\
(1.70)\end{array}$ & $\begin{array}{c}9.7 \\
(2.67)\end{array}$ & $\begin{array}{l}10.0 \\
(3.59)\end{array}$ \\
\hline $\begin{array}{l}\text { Thoracic } \\
\text { angle range } \\
\left({ }^{\circ}\right)\end{array}$ & $\begin{array}{l}\text { Trans } \\
\text { verse }\end{array}$ & $\begin{array}{c}3.0(2.22) \\
*\end{array}$ & $\begin{array}{c}3.3 \\
(1.15) *\end{array}$ & $\begin{array}{c}6.6 \\
(2.91)\end{array}$ & $\begin{array}{c}7.8 \\
(3.82) *\end{array}$ & $\begin{array}{c}3.6 \\
(1.46)\end{array}$ & $\begin{array}{c}4.3 \\
(1.54)^{*}\end{array}$ & $\begin{array}{c}9.8 \\
(5.06)\end{array}$ & $\begin{array}{c}9.4 \\
(5.42)\end{array}$ \\
\hline $\begin{array}{l}\text { Trunk angle } \\
\text { range }\left({ }^{\circ}\right)\end{array}$ & $\begin{array}{l}\text { Sagitt } \\
\text { al }\end{array}$ & $2.3(1.35)$ & $\begin{array}{c}2.5 \\
(1.82)\end{array}$ & $\begin{array}{c}8.5 \\
(5.16) *\end{array}$ & $\begin{array}{c}8.8 \\
(5.25)^{*}\end{array}$ & $\begin{array}{c}5.3 \\
(1.66)\end{array}$ & $\begin{array}{c}6.1 \\
(3.41)\end{array}$ & $\begin{array}{c}2.6 \\
(0.97)\end{array}$ & $\begin{array}{c}2.4 \\
(0.86)\end{array}$ \\
\hline $\begin{array}{l}\text { Trunk angle } \\
\text { range }\left({ }^{\circ}\right)\end{array}$ & $\begin{array}{l}\text { Coron } \\
\text { al }\end{array}$ & $\begin{array}{c}4.0(1.36) \\
*\end{array}$ & $\begin{array}{c}4.5 \\
(1.46) *\end{array}$ & $\begin{array}{c}5.9 \\
(2.62) *\end{array}$ & $\begin{array}{c}6.0 \\
(2.93) *\end{array}$ & $\begin{array}{c}11.6 \\
(7.56)^{*}\end{array}$ & $\begin{array}{c}13.0 \\
(9.97)^{*}\end{array}$ & $\begin{array}{c}10.5 \\
(2.87)\end{array}$ & $\begin{array}{l}10.8 \\
(3.14)\end{array}$ \\
\hline $\begin{array}{l}\text { Trunk angle } \\
\text { range }\left({ }^{\circ}\right)\end{array}$ & $\begin{array}{l}\text { Trans } \\
\text { verse }\end{array}$ & $\begin{array}{c}2.9(2.60) \\
*\end{array}$ & $\begin{array}{c}3.3 \\
(1.40)^{*}\end{array}$ & $\begin{array}{c}5.7 \\
(2.58)^{*}\end{array}$ & $\begin{array}{c}5.9 \\
(3.12)^{*}\end{array}$ & $\begin{array}{c}17.5 \\
(11.78) \\
*\end{array}$ & $\begin{array}{c}19.6 \\
(13.26) \\
*\end{array}$ & $\begin{array}{c}17.0 \\
(5.27)\end{array}$ & $\begin{array}{c}17.1 \\
(5.10)\end{array}$ \\
\hline $\begin{array}{l}\text { Pelvis angle } \\
\text { range }\left({ }^{\circ}\right)\end{array}$ & $\begin{array}{l}\text { Sagitt } \\
\text { al }\end{array}$ & $\begin{array}{c}3.3(1.75) \\
*\end{array}$ & $\begin{array}{c}4.0 \\
(2.32) *\end{array}$ & $\begin{array}{c}6.0 \\
(3.11)^{*}\end{array}$ & $\begin{array}{c}6.9 \\
(4.08)\end{array}$ & $\begin{array}{c}4.5 \\
(2.51)^{*}\end{array}$ & $\begin{array}{c}4.4 \\
(2.93)^{*}\end{array}$ & $\begin{array}{c}5.4 \\
(1.59)\end{array}$ & $\begin{array}{c}5.2 \\
(1.22)\end{array}$ \\
\hline $\begin{array}{l}\text { Pelvis angle } \\
\text { range }\left({ }^{\circ}\right)\end{array}$ & $\begin{array}{l}\text { Coron } \\
\text { al }\end{array}$ & $2.2(0.92)$ & $\begin{array}{c}2.4 \\
(1.14)\end{array}$ & $\begin{array}{c}10.1 \\
(5.56)^{*}\end{array}$ & $\begin{array}{c}11.4 \\
(7.20)^{*}\end{array}$ & $\begin{array}{c}4.4 \\
(1.68)\end{array}$ & $\begin{array}{c}4.8 \\
(2.35)\end{array}$ & $\begin{array}{c}2.5 \\
(0.70)\end{array}$ & $\begin{array}{c}2.6 \\
(0.95)\end{array}$ \\
\hline $\begin{array}{l}\text { Pelvis angle } \\
\text { peak }\left({ }^{\circ}\right)\end{array}$ & $\begin{array}{l}\text { Obliq } \\
\text { uity }\end{array}$ & $\begin{array}{c}11.3 \\
(4.81)\end{array}$ & $\begin{array}{l}10.8 \\
(4.96)\end{array}$ & $\begin{array}{c}18.9 \\
(9.46)^{*}\end{array}$ & $\begin{array}{c}19.5 \\
(11.04) \\
*\end{array}$ & $\begin{array}{l}12.6 \\
(5.38)\end{array}$ & $\begin{array}{c}13.7 \\
(5.34) *\end{array}$ & $\begin{array}{c}8.3 \\
(4.82)\end{array}$ & $\begin{array}{c}8.3 \\
(5.14)\end{array}$ \\
\hline $\begin{array}{l}\text { Pelvis angle } \\
\text { range }\left({ }^{\circ}\right)\end{array}$ & $\begin{array}{l}\text { Trans } \\
\text { verse }\end{array}$ & $\begin{array}{c}3.8(1.43) \\
*\end{array}$ & $\begin{array}{c}3.7 \\
(2.07) *\end{array}$ & $\begin{array}{c}3.8 \\
(1.03)^{*}\end{array}$ & $\begin{array}{c}4.0 \\
(2.19)^{*}\end{array}$ & $\begin{array}{c}53.6 \\
(17.48) \\
*\end{array}$ & $\begin{array}{c}61.5 \\
(18.82) \\
*\end{array}$ & $\begin{array}{c}15.0 \\
(5.24)\end{array}$ & $\begin{array}{c}14.6 \\
(5.28)\end{array}$ \\
\hline $\begin{array}{l}\text { Hip angle } \\
\text { range }\left({ }^{\circ}\right)\end{array}$ & $\begin{array}{l}\text { Sagitt } \\
\text { al }\end{array}$ & $\begin{array}{c}2.6(1.60) \\
*\end{array}$ & $\begin{array}{c}2.7 \\
(1.98) *\end{array}$ & $\begin{array}{c}44.2 \\
(13.70) \\
*\end{array}$ & $\begin{array}{c}41.7 \\
(10.89) \\
*\end{array}$ & $\begin{array}{c}7.8 \\
(4.30)^{*}\end{array}$ & $\begin{array}{c}8.2 \\
(4.09) *\end{array}$ & $\begin{array}{c}38.6 \\
(6.89)\end{array}$ & $\begin{array}{c}37.8 \\
(5.11)\end{array}$ \\
\hline $\begin{array}{l}\text { Hip angle } \\
\text { range }\left({ }^{\circ}\right)\end{array}$ & $\begin{array}{l}\text { Coron } \\
\text { al }\end{array}$ & $\begin{array}{c}4.4(2.61) \\
*\end{array}$ & $\begin{array}{c}3.9 \\
(2.19)^{*}\end{array}$ & $\begin{array}{c}9.1 \\
(5.76)\end{array}$ & $\begin{array}{c}9.0 \\
(4.55)\end{array}$ & $\begin{array}{c}5.7 \\
(3.26) *\end{array}$ & $\begin{array}{c}5.7 \\
(3.17)^{*}\end{array}$ & $\begin{array}{c}9.4 \\
(2.31)\end{array}$ & $\begin{array}{c}9.5 \\
(1.92)\end{array}$ \\
\hline $\begin{array}{l}\text { Hip angle } \\
\text { range }\left({ }^{\circ}\right)\end{array}$ & $\begin{array}{l}\text { Trans } \\
\text { verse }\end{array}$ & $\begin{array}{c}3.1(1.24) \\
*\end{array}$ & $\begin{array}{c}3.6 \\
(1.24) *\end{array}$ & $\begin{array}{c}5.9 \\
(2.41)^{*}\end{array}$ & $\begin{array}{c}5.5 \\
(3.06) *\end{array}$ & $\begin{array}{c}8.3 \\
(3.50)\end{array}$ & $\begin{array}{c}6.4 \\
(3.30)^{*}\end{array}$ & $\begin{array}{c}10.5 \\
(3.97)\end{array}$ & $\begin{array}{c}10.8 \\
(3.37)\end{array}$ \\
\hline
\end{tabular}

* Significant difference compared with walking 


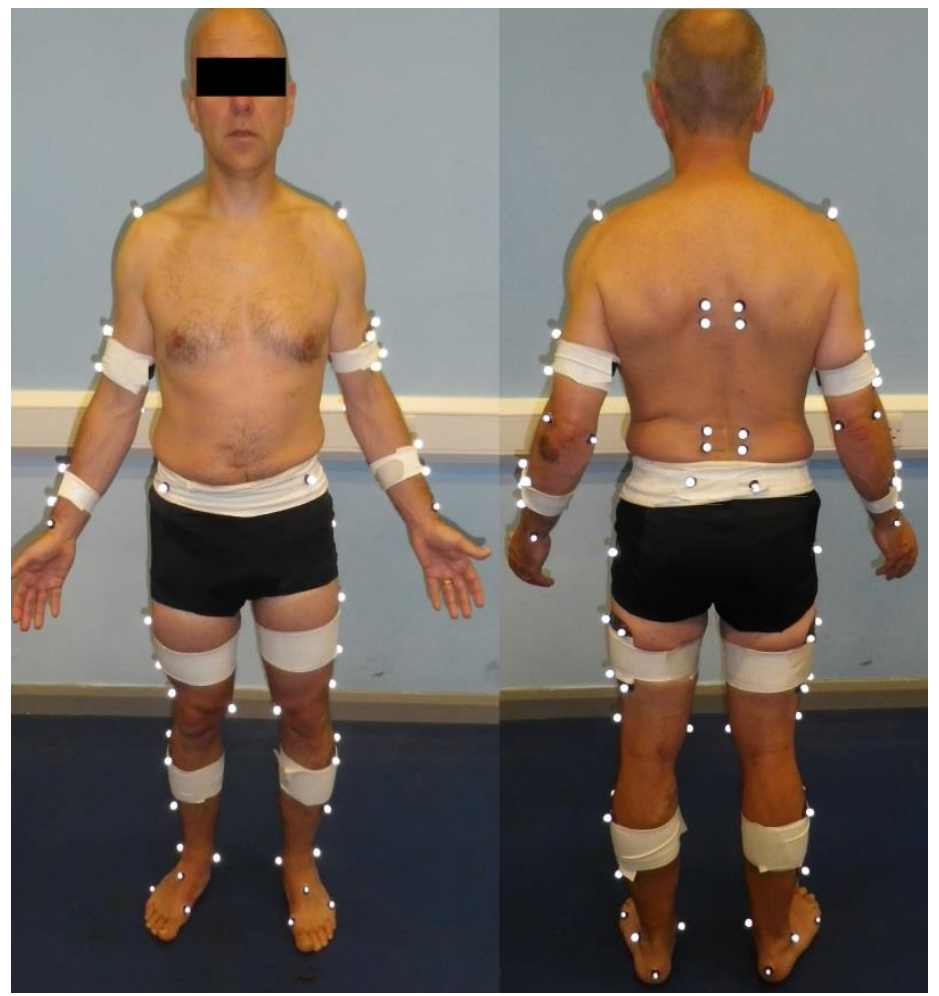

Figure 1: Marker placement based on the Calibrated Anatomical Systems Technique (CAST)

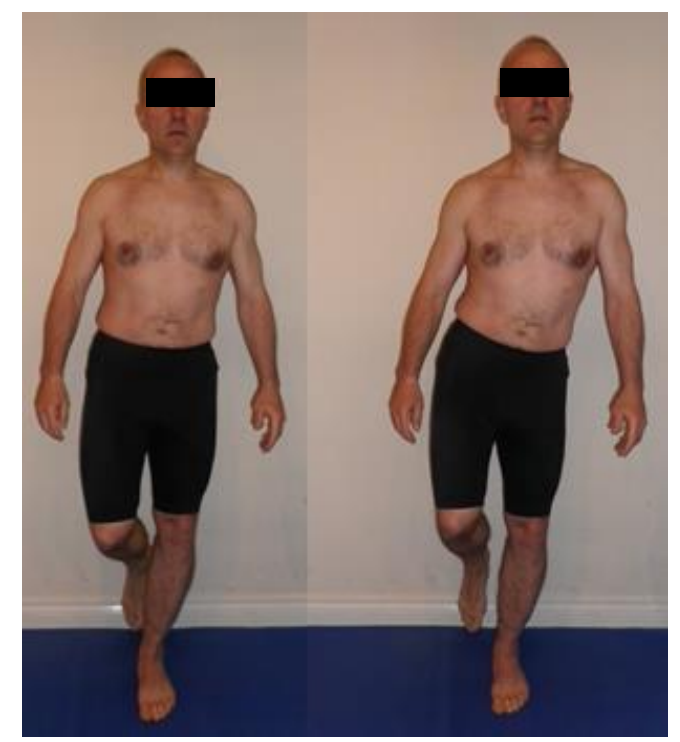

Figure 2: Study Trendelenburg Test method; (A) start / finish position (B) Trendelenburg Test position $^{3}$ 


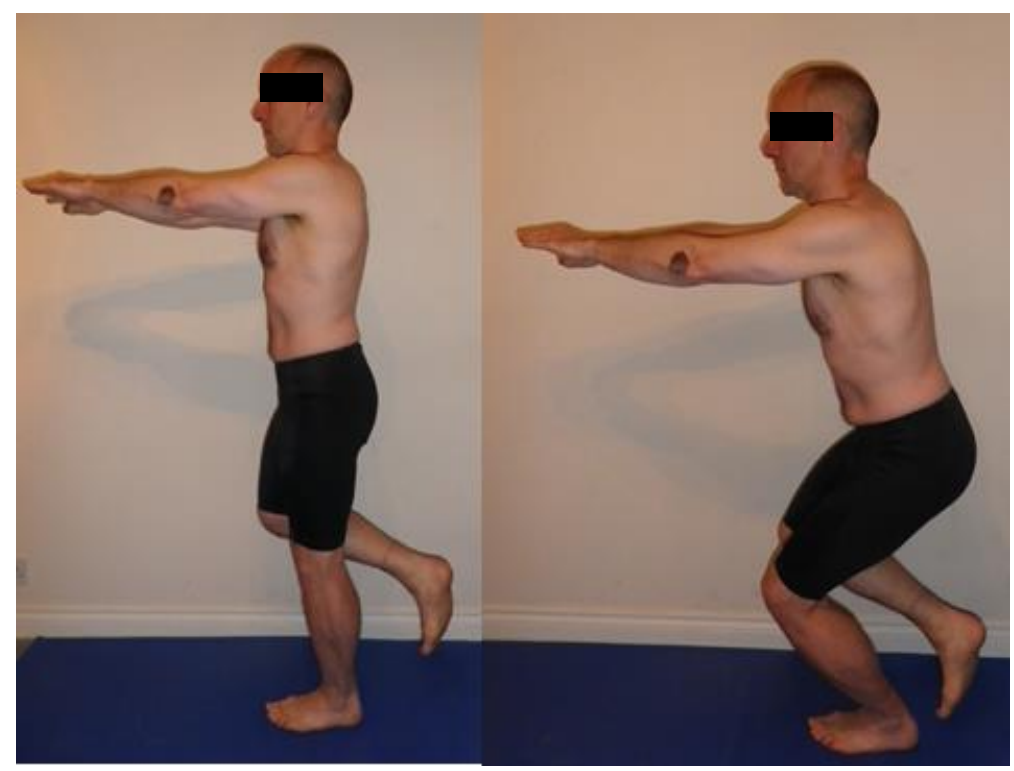

Figure 3: Study Single Leg Squat method; (A) start / finish position (B) Squat position ${ }^{26}$

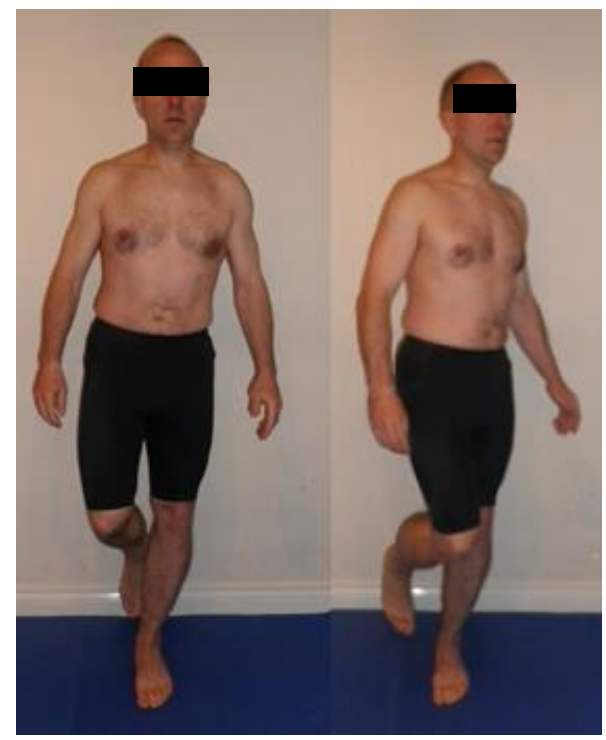

Figure 4: Study Corkscrew Test method; (A) start / finish position (B) Corkscrew position 